\title{
Serving the bibliographic needs of scholars in Tanzania: a case study of the Tanzania Library Services Board
}

\author{
Alli Mcharazo
}

\begin{abstract}
Introduction
What difference does up-to-date bibliographic information make in a poor developing country like Tanzania? The honest answer is none at all, if it is not possible to go beyond the bibliographic reference to the actual item itself. For many African scholars, browsing through a bibliography is like looking at goods in a shop window: pointless without the ability and means to acquire what is on display. That said, bibliographies are of great value to scholars in institutions with libraries that do possess the means to build up and maintain good collections.

This is an overview of the bibliographic needs of Tanzania's scholars, and of some of the issues that they and their libraries face. In particular, I discuss: the need for bibliographies, the bibliographic needs of scholars, how well their needs are addressed, the state of national bibliographies, what more can be done to make African scholarship available in Europe and America, the roles for libraries in Africa, and the way forward.

The essay uses the specific case study of the Tanzania Library Services Board (TLSB). TLSB is a national-cum-public library system that, at the moment, operates a national library, and a network of nineteen regional and fifteen district libraries. This system serves quite a number of scholars, and publishes the Tanzania National Bibliography (TNB). The case study includes findings from a small survey of scholars who visit the library, and from TLSB staff. TLSB statistics and other library and documentary sources support the analysis.
\end{abstract}

\section{Background to TLSB}

TLSB is a parastatal organization under the Ministry of Education and Vocational Training, established by an Act of Parliament in 1963, which was superseded by a subsequent Act in 1975. This Act confers upon TLSB a wide range of responsibilities, including the establishment and administration of libraries and documentation centres, the training of information personnel,

\footnotetext{
* Alli A.S. Mcharazo, Cert. Law, Dip Lib, BA, MA, PhD, FLA, is Director General of Tanzania Library Services Board. He has worked as Director of Library Services at Muhimbili University of Health and Allied Sciences, and as Chief Librarian of the University College of Lands and Architectural Studies, a constituent College of the University of Dar es Salaam. He has taught at Thames Valley University, London, and acted as a consultant for Unesco, Book Aid International, the Southern African Book Development Education Trust, and the Tanzania Commission for Science and Technology. He has authored and contributed a significant number of papers on library and information studies to national and international journals.
} 
and consultancy on issues pertaining to libraries and information centres in Tanzania.

The main objectives of TLSB are to provide information and reading resources to the general public, including students, researchers, professionals, civil servants, peasants, business people, politicians, and the newly literate. TLSB's vision is to be a reputable institution in the provision of timely access to current and relevant information, and, diligently and efficiently, to provide high quality services to the general public for educational development in the global context. TLSB's mission is to play a leading role as an information institution, putting knowledge available in libraries and on the internet to work for the benefit of the public, and to support life-long learning for society at large.

Additional to running a network of regional and district public libraries, TLSB also acts as the national copyright library of Tanzania. It is duty-bound to acquire and store national literary output for future use. The TLSB Act 1975 (United Republic of Tanzania 1975) states that:

It shall be the duty of every person who prints or produces or causes to be printed or produced in Tanganyika any book or other literary work intended for sale or public distribution or exhibition ... to supply the Board, free of charge, not less than two copies of such book or other literary work ...

The materials deposited as a result of the above law form a basis for compiling TNB by the National Bibliographic Agency (NBA) and others. Currently, it is estimated that the NBA holds about 28,008 volumes (14,004 titles) of books and other literary materials, and 159,349 volumes (734 titles) of periodicals used by scholars and the general public.

\section{The need for bibliographies}

The success of good scholarship depends so much on the availability of scholarly reading materials and literature. Scholars at all levels require information in all sorts of formats to make their work a success. Scholarly materials, like other information materials, are produced at an exponentially increasing rate and in different locations. Not knowing what has been published deprives scholars of important information. Ng'ang'a (1988) reminds us that the

... information explosion of this century has made it imperative that we look for better ways to identify information on many subjects no matter where this information may be found and in what form it has appeared ... The only way in which librarians and documentalists everywhere can hope to control the vast amount of materials now flooding the world is if each country made certain to record, in a standardized manner, all material published within its border.

It is in this context that bibliographies and bibliographic control schemes are of paramount importance. Research and project work usually begins where others have stopped and found. To find, relevant bibliographies and other sources must be consulted. It should be in the interest of libraries and other information units to see that scholars' bibliographic needs are addressed; secondly, to address those needs by providing relevant information and scholarly materials. 
Bibliographies make public information on sources by Tanzanian authors, editors and publishers. Such materials include books, journals, theses and non-print media. Bibliographies are used as guides to materials important to reference, research, consultancy, planning, training, and specific subjects. Information units, such as libraries, must ensure that they give their users the service they deserve. A bibliography is in itself a form of quality assurance. It can be regarded as a measure that is built into the catalogue or database to ensure the quality of interaction between the user and information (Snyman 2000).

Modern thinking about bibliographies is that they should enable information services to share resources and catalogue records, provide a quality service to users, and develop effective online systems. Moreover they could be used to prepare recurrent specialized bibliographies. The emphasis is now on providing bibliographies in electronic format. The British National Bibliography (BNB), the American National Union Catalog, Whitaker's Books in Print (now incorporated into Bookdata online) and others are available on $\mathrm{CD}$ and in other electronic formats.

A study of TNB and other bibliographies published in and outside Tanzania shows that the national literary output is increasing. While in the early 1980s the country was producing an average of about 200 volumes per annum, to date about 600 to 800 volumes are published. TNB provides a list that represents almost all subjects covered by the Dewey Decimal Classification system. The social sciences are among the areas best represented. This is no surprise, as political science, economics, public finance, law and education are of interest to higher education institutions, universities and colleges. Some universities have their own publishing arm. A good example in Tanzania is Dar es Salaam University Press, which publishes and prints academic publications. Other well-established areas are science, technology and children's books. Other material is published by government and non-government organizations. Kaungamno and Ilomo (1979) summarized the situation as follows:

Both government and quasi-governmental institutions conduct research in their fields of operation and issue an immense amount of literature in report forms, bulletins, monographs, handbooks, etc. This wealth of materials, if it is to be useful and enable East Africa to progress, has to be assembled, organized and made available for use by the East African public ... Librarians and documentalists have to develop devices which will facilitate information retrieval and its use for utilitarian purposes.

Most of these materials are found in the TLSB system, research institutions, government ministries and departments and universities such as the University of Dar es Salaam, Sokoine University of Agriculture, and Muhimbili University of Health and Allied Sciences. Others are available in bookshops.

Easy availability of these resources is of paramount importance to scholars and researchers. Political, historical and development research requires an understanding of what is already published, to save time and avoid repetition. It is obvious, therefore, that if scholars are deprived of this information, the quality of their work will be seriously diminished and they will be unable to 
realize their full potential. In some cases, their students and societies at large will be intellectually impoverished.

\section{Bibliographic needs of Tanzania's scholars}

Every user who visits the library has their own needs and comes with great expectations about the service. The objective of the library is to meet such needs. In order to do so, a number of reference tools have to be consulted. Bibliographies are among the reference tools widely used to assist users in locating relevant resources in the library. A small survey that involved NBA records, reference interrogation, and enquiries from scholars revealed the following.

\section{Research}

Some researchers use bibliographies to discover materials and publications related to the topic on which they are working. Lecturers, researchers and social scientists in particular are the ones mostly using bibliographies at NBA. They are usually looking for information and any documents that have been published in their fields of research. This information is used as a basis or take-off point for their studies. Many of these users come from universities and other tertiary level institutions.

Keeping abreast of new developments

Some scholars are only interested in materials that have been published on a given topic. They want to be aware of, and be updated about, new developments in their areas of interest. This category does not necessarily involve researchers per se, but other scholars, professionals and practitioners in various fields such as education, health, agriculture, book production, literature in both Kiswahili and English, social sciences, science, technology, and politics. NBA registers quite a number of users whose interest is to know, for example, what has been written on subjects such as HIV/Aids, children's books, fiction and politics.

Location of additional materials

In addition, bibliographies are used to locate additional materials on a certain subject on which they have conducted research before.

Use by other information units

The bibliographic data provided is used by other libraries and individual scholars in constructing their catalogues or bibliographic lists. The bibliographic information is used to prepare recurrent specialist bibliographies.

\section{How well are bibliographic needs met by existing services?}

National Bibliographic Agency

The NBA is a division of TLSB under the Department of Library Services Management. Its primary objective has been and still is the procurement of the national imprint. It lists and describes procured publications and publishes bibliographic records for these publications so that they become known nationally and internationally. The agency is also the National Centre 
for International Standard Book Number (ISBN) and International Standard Serial Number (ISSN). It operates under five main sections: Document Procurement, National Standard Serial and Book Numbering, Document Processing and Production of National Bibliography, Dissemination of Information, and Documentation Services. The division offers customer services, which include staff attending to customer needs promptly, accurately assessing and meeting their information needs. It also provides bibliographic records of the literature available in the country. These bibliographic records are prepared out of the literature and other reading materials received under the legal deposit law. NBA is a national legal depository library.

Availability of national bibliographies

The standard arguments for producing national bibliographies include: bibliographic control, listing the nation's publications for current and future use, potential for analysis of what is published within a country, and providing a full bibliographic record for everything published in that country. In the years after independence, librarians viewed the compilation of national bibliographies as an essential task. NBA is responsible for compiling TNB, which was first published in 1969 with the title Printed in Tanzania. The title Tanzania National Bibliography was adopted in 1977, immediately after the International Congress on National Bibliographies organized by Unesco and the International Federation of Library Associations (IFLA). However, the basis of producing the bibliography is the legal deposit provision under the TLSB Act that was passed by the National Assembly in 1975. TNB was issued annually until 1989, with monthly lists being produced from 1983 to 1988 .

For those regional libraries within the TLSB system, TNB is available free of charge. Although the general subscription rate is not so highly priced, the response is not encouraging as the number of subscribers continues to remain low. This is mainly because the TNB is published inconsistently. There are about thirty overseas subscribers of which only fourteen are active. These subscribers represent mainly universities, university libraries and national libraries in Europe and the US. Examples of subscribers from Europe are Cambridge University, Nordic Africa Institute, International Labour Office, Institute of Commonwealth Studies, Edinburgh University, British Library, Bibliothèque Nationale de France, Lenin State University, the Bodleian Library, and the School of Oriental and African Studies. Those from the US include Duke University, Columbia University, Harvard University, Indiana University, Northwestern University and the University of California. Others are the National Library of Singapore and University of Sydney. In Africa, only the University of Botswana and South African National Library subscribe. TNB functions as a practical information tool in the sense that it can be used as a selection tool, since it provides detailed information, making it possible to identify a document, and provides a statistical record of the country's publishing industry. The bibliographic data provided may be used by other libraries which are constructing catalogues or bibliographic lists.

TNB is available on subscription and also on exchange with other African national bibliographies. This follows the recommendation of the 1983 African Conference on Bibliographic Control (ASCOBIC) and several overseas organizations. It is on this same basis that TLSB's NBA provides 
national bibliographies of the neighbouring countries. These include Kenya National Bibliography, Uganda National Bibliography, Malawi National Bibliography, Botswana National Bibliography and Madagascar National Bibliography. Other national bibliographies such as British National Bibliography are also provided.

Provision of other specialized bibliographies

A bibliography is something more than simply a handy reference tool. It is a device for helping to define the field of any subject or area. It can act as a research tool. What begins as systematic checking of essential information about every book listed in the bibliography ends up as a useful collection of data. It can therefore be much more than just a means of locating information.

The library maintains many different bibliographies that are made available to users to locate resources housed at the library and in other special and academic libraries. Some of these bibliographies are general; TNB is an example of a general bibliography produced by the TLSB on yearly basis. In addition, there are also specialized bibliographies compiled by different institutions on certain topics and subjects.

Bibliographic information is used as a service to users of information, acting as a precise indicator of the relevance of literature to scholars. It is also used for current awareness, to assist users directly in the identification of access to potentially relevant materials and publications. Some of the bibliographies that are available include:

- Perspectives of Land Degradation and Conservation in Tanzania: An Annotated Bibliography

- Women in Tanzania: An Analytical Bibliography

- Mwalimu fulius Kambarage Nyerere: A Bio-Bibliography

- Human Settlements in Tanzania: An Interdisciplinary Bibliography

- Urbanisation, Urban Planning and Urban Life in Tanzania: An Annotated Bibliography

- Agricultural Development in SADCC Countries: A Bibliography

- Bibliography of the Coastal and Marine Environment of the Western Indian Ocean Region

- Periodicals in Tanzanian Libraries: A Union List.

An investigation of these bibliographies has revealed that almost all of them have been prepared by scholars or scholarly organizations, intended for scholars and the general public. Universities and other academic institutions in Tanzania play a leading role in publishing these bibliographies. The University of Dar es Salaam is a good example. There is also evidence of collaboration between academic institutions in Tanzania and others overseas.

Availability of other bibliographies

Apart from bibliographies published in Tanzania, the NBA also provides some bibliographies that have been published overseas. On occasion, scholars, researchers and others will enquire about sources that are not available in the library or in the country. They are provided with 
bibliographies that have been published overseas. Some of these bibliographies are

- The Bibliography of Africa: Collected Papers of the National Conference

- Nigerian Publications

- South African Bibliography

- Publishing and Book Development in Sub-Saharan Africa: An Annotated Bibliography

- A World Bibliography of African Bibliographies

- Africa Bibliography.

The library maintains a catalogue of all holdings. This includes a subject, author and title catalogue. It also acquires trade catalogues and subject lists through the legal deposit law.

\section{Analysis of the state of Tanzania National Bibliography}

The bibliography collections in public and academic library systems are small, and have failed to satisfy demand from scholars. This small survey has also established that the available collections are outdated. Many important subjects still lack bibliographies. Many bibliographies were compiled in the 1970 s and 1980s. Only a few were published in the 1990s, and none at all, so far, in the twenty-first century, except for the TNB. It is obvious that bibliographies are not compiled at the necessary pace, and that this is certainly detrimental to the production of scholarly works. The study has established that some of the reasons include a lack of bibliographers or experienced bibliographers, a lack of interest in compiling bibliographies, inadequate resources (mainly funds) to compile and publish bibliographies, and failure on the part of librarians to purchase bibliographies within or outside the country due to the low priority they attach to them.

TNB lists all publications legally deposited. These include published and mimeographed publications such as monographs, pamphlets, reports, theses, conference proceedings, and first issues of new serial titles (journals). Tanzania ensures that it complies with national and international standards and technological developments. The description of materials in the national bibliography follows the Anglo-American Cataloguing Rules (AACR2) and the International Standard Bibliographic Description (ISBD).

As in many African countries, TNB is behind schedule due to financial constraints and lack of human resources. Since 1990, TLSB has been published in volumes covering three years. Recently an issue covering the years 1999-2001 was published and distributed. It is within TLSB's plans to produce two issues before the end of June 2008. These will cover the years $2002-4$ and 2005-6 respectively. The printed national bibliography is available on subscription and also on exchange with other African national bibliographies (following the recommendation of ASCOBIC 1983) and with several overseas organizations.

TNB functions as a practical information source in the sense that it can be used as a selection tool since it provides the details of publication, which make it possible to identify a document, providing a statistical record of the country's publishing industry. The bibliographic data provided may be used 
by other libraries which are constructing their catalogues or bibliographic lists, both nationally and internationally.

Although progress is encouraging, problems are evident. Under the TLSB Act of 1975, anybody producing publications in the country is required to deposit two copies of each title to the director of TLSB. Many documents still escape the attention of the agency, especially government publications. The publishing mechanism in the government ministries and departments is so complicated that it is impossible to know which division or section deals with publications. It certainly complicates the work of librarians to get hold of these important documents. It would have been better for individual ministries and departments to realize the importance of setting up publication sections to make it easier for TLSB to collect the documents, and also to enable individual ministries to know as quickly as possible about their literary output. This idea is now not new any more, as the Draft Media Bill, still in the making and under serious discussion, encourages the same practice.

\section{What more can be done to make African scholarship available outside Africa?} The arguments here demonstrate that national bibliographies are of use to scholars. TNB, for example, lists many Kiswahili titles. It is interesting, however, to note that so far there has never been a Kiswahili bibliography despite the fact that many books and other publications have been published in Kiswahili. The absence of bibliographies in other African languages is also evident. It would be interesting to conduct a survey of Kiswahili scholars in Tanzania, other parts of East Africa and elsewhere in the world to see to what extent they are aware of TNB and other bibliographic sources. It is also important that scholars are encouraged to compile bibliographies in Kiswahili.

Staff at the NBA have established that these bibliographies are not used frequently. It was also established that one of the reasons for this is the fact that they have not been well publicized to scholars and other current and potential users. Africa Bibliography is being distributed free of charge to eighty university libraries in Africa. ${ }^{1}$ This is definitely a step in the right direction. Tanzania's libraries and librarians need to follow suit by being more pro-active. They need to promote bibliographies to their scholars and other users.

African bibliographies are rarely indexed in the major international databases, a problem made worse by the inaccessibility of printed materials and research published in the region, much of which is based on local data not available in the international literature. This inability to learn about and access African materials is frustrating to both African and overseas scholars. There is a need to improve dissemination of African information. The best way is to provide effective online systems through expanding the scope of information by using information communication technologies.

Equally, libraries must ensure that the catalogue records created by specific libraries fit into a larger universe to enable other countries to share their resources. This is very important because it has become impossible for

\footnotetext{
${ }^{1}$ By arrangement with the International African Institute, Book Aid International and Edinburgh University Press.
} 
libraries to collect all materials to satisfy their users' needs, due to economic restrictions, and the increase in published sources of information.

In this period of information technological advancement, we cannot escape the question: where do African bibliographies stand in the Google age? In the case of TLSB, perhaps not much has been done, apart from compiling it on a computer and using free Unesco CDS/ISIS software. In terms of access, the TNB is not yet available online. Many bibliographies are, however, available online and can be easily publicized and accessed. There is certainly a need to move to making bibliographies available in electronic format. With the introduction of information and communication technologies and the internet at TLSB in 2007, it is hoped that bibliographies will be easily produced, stored, accessed and disseminated. The right technology for producing bibliographies needs to be in place. Library websites are another significant communication medium for users, providing information on services and collections of other libraries.

\section{What roles for libraries in Africa?}

In Tanzania, bibliographies are not adequately compiled. The few that are available are not fully utilized. Earlier, Kaungamno and Ilomo warned that

East Africa ought to be conscious of its bibliographic activities laxity and the librarians', and documentalists' or archivists' tendency to ignore bibliographic work as if it is not their responsibility. All East Africans engaged in library and information services infrastructure have as a result become over-dependent upon our overseas friends who take great interest in East Africa's literary output and compile accession lists, bibliographies, catalogues and so on ... (Kaungamno and Ilomo 1979)

As a way of improving production and making their publications popular so that they attract optimal utilization, African countries should ensure that they publish national bibliographies and subject-based bibliographies on time and at frequent intervals. To achieve this, it is important that librarians and other information professionals are trained and encouraged in the compilation of bibliographies. It is very important for African member countries to try, as much as possible, to create awareness of the importance of national bibliographic control among members of the public and decision-makers.

Today in this digital age, as the case study of TLSB in Tanzania has shown, many people, especially Africans, are increasingly disadvantaged in their access to information because they do not have access to the internet. To improve the situation, libraries are urged to introduce ICTs. This would make the whole process of compiling, accessing and distributing bibliographies much easier. Through web-based services, bibliographies could be easily shared amongst libraries and accessed by scholars and other users in and outside Tanzania.

Most libraries lack competent bibliographers. When narrating the fate and state of training for bibliographic control at the IFLA Jerusalem conference, Snyman (2000) observed that

In the recent past much has been written about the reasons for the shortage of competent bibliographers. Library schools also came under fire for contributing to the problem of a shortage of good cataloguers. Courses in bibliographic control have also been criticized ... a lot of emphasis is placed on the course content, but not on the methods of training ... 
It is quite clear therefore that a bibliographer requires certain tools, a base of detailed knowledge to utilize the tools, and a range of practical skills in order to perform the work fully. Practical work and on-the-job experience are also considered a necessity in cataloguing courses. To gain cataloguing experience, students are required to work for a couple of weeks in the library. This should be a challenge to library schools in Tanzania. It should be in the interest of the schools not only to teach aspects of bibliography but also to provide their students with more hands-on skills that would enable them to compile bibliographies. As for the continuity of compiling bibliographies, it is advised that scholars should be commissioned to do the work.

The task of ensuring that all publications produced within a country reach the national library for preservation and national bibliographic control purposes must not be shouldered by one institution. Other libraries and information centres must assist in the objective of national bibliographic control, if we are to move ahead.

\section{Conclusion}

The TLSB experience provides us with very useful information, and a reminder that the importance of bibliographies to African scholars and other segments of society cannot be overemphasized. What needs to be emphasized, and re-emphasized, is that bibliographies are not produced at the requisite level, and that those available are under-utilized. This means the quality of scholarly materials will naturally diminish. If this happens, the blame will be attributed to the library and information professions, as they have been entrusted with the responsibility of compiling or commissioning compilers and making the bibliographies accessible to scholars and others. Mchombu (2007) has observed that

Information sharing is vital to ensure that information does not stay in silos isolated from the day to day problems facing society. Without an active communication programme in place information becomes static and stays in the same place and does not add value to the production process in society. Thus the role of information centers must also include clear information delivery strategies to deliver information in appropriate formats, languages and subject matters.

The publication and effective distribution of bibliographies in Tanzania and elsewhere would certainly be a step towards Universal Bibliographic Control and the realization of the ideals set out in this essay. Bibliography as an issue is not of course on the same level as the eradication of illiteracy, the struggle against HIV/Aids, the preservation of the environment, gender balancing, poverty reduction, and the other targets in Tanzania's national agenda. But information has an important role to play in achieving these goals, and bibliographic information is an important part of the picture.

\section{Bibliography}

Campbell, John (1995) Urbanisation, Urban Planning and Urban Life in Tanzania: an annotated bibliography. Hull: University of Hull.

CTA (1990) Agricultural Development in SADCC Countries: a bibliography. Wageningen: CTA.

Hannan-Andersson, Carolyn (1990) Human Settlements in Tanzania: an interdisciplinary bibliography. Stockholm: Swedish Council for Building Research.

Kaungamno, E.E. and C.S. Ilomo (1979) Books Build Nations: vol. 1, library services in West and East Africa. London: TransAfrica. 
Kenya National Library Service (2007) Kenya National Bibliography 2005. Nairobi: Kenya National Library Service.

Kikula, I.S., C.G. Mung'ong'o, and R.D. Jengo (1990) Perspectives of Land Degradation and Conservation in Tanzania: an annotated bibliography. Dar es Salaam: University of Dar es Salaam.

Mascarenhas, Ophelia and Marjorie Mbilinyi (1983) Women in Tanzania: an analytical bibliography. Uppsala: Swedish International Development Authority.

Mchombu, K.J. (2007) 'Harnessing Knowledge Management for Africa's Transition to the 21st Century' in Alli Mcharazo and Sjoerd Koopman (eds) Librarianship as a Bridge to an Information and Knowledge Society in Africa. The Hague: International Federation of Library Associations and Institutions.

Mlaki, Theophilus E. (1981) 'Bibliographic Control of the Current National Literature of Tanzania', Master's dissertation, Loughborough University of Technology.

Mwenegoha, H.A.K. (1976) Mwalimu fulius Kambarage Nyerere: a bio-bibliography. Dar es Salaam: Foundation Books Limited.

Ng'ang'a, James M. (1988) 'Bibliographic Control in Eastern and Southern Africa: state of art' in Management of Information Systems: reports and papers of a training course held in Arusha from 11 to 22 April 1988. Arusha: Deutsche Stifung für Internationale Entwicklung (DSE).

Snyman, Retha (MMM) (2000) 'Bibliographic Control - Is the Current Training Still Relevant?' Paper Presented at 66th IFLA Council and General Conference, Jerusalem, Israel, 13-14 August 2000. <http://www.ifla.org/IV/ifla66/papers/108-183e.htm>

Tanzania Library Services Board (2001) Tanzania National Bibliography: 1999-2001. Dar es Salaam: Tanzania Library Services Board.

United Republic of Tanzania (1975) Tanzania Library Services Board, Act No. 6 of 1975.

University of Dar es Salaam (1999) Bibliography of the Coastal and Marine Environment of the Western Indian Ocean Region. Dar es Salaam: University of Dar es Salaam. 